\section{Practitioner evaluation of a novel online integrated oral health and risk assessment tool: a practice pilot}

\author{
M. Busby, ${ }^{1}$ E. Chapple, ${ }^{2}$ R. Matthews ${ }^{3}$ and I. L. C. Chapple ${ }^{* 4}$ \\ VERIFIABLE CPD PAPER
}
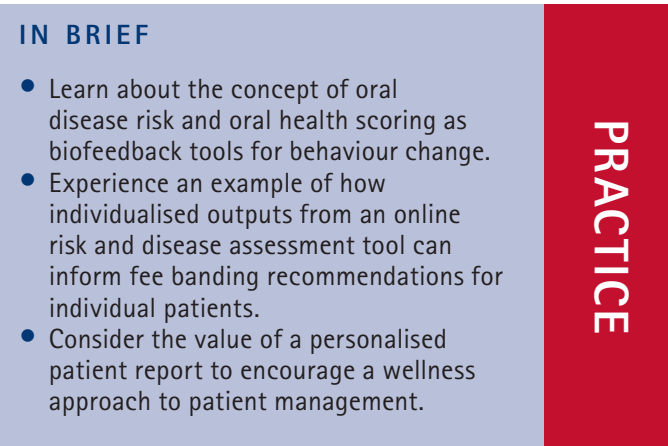

\begin{abstract}
Aim To report the development and evaluation of an evidence-based, online, patient assessment tool, capable of measuring oral health status, future disease risk and capitation fee guidance. Methods An online integrated oral health and risk assessment tool called DEPPA was developed, incorporating 1) PreViser ${ }^{\mathrm{TM}}$ risk scores for periodontal disease, caries, noncarious tooth surface loss and oral cancer, 2) revised versions of Denplan Excel's Oral Health Score and 3) capitation fee guidance score. DEPPA was piloted by 25 dentists who provided quantitative and qualitative feedback. Results Six hundred and forty assessments were performed. There was strong agreement on the need for such a tool, that it constituted a comprehensive assessment and supported good patient communication. The validity of the system was perceived as sound and the revised capitation fee guidance broadly welcomed. While some deemed the caries risk scoring algorithm to be too sensitive, the 30\% high/very high risk rating is consistent with current rates of active caries in UK adults. Conclusions A viable online oral health and risk-assessment tool has been developed (DEPPA) that will allow dental teams to measure oral health status, future disease risk and receive ongoing guidance on capitation fee setting. The indications are that DEPPA could be a valuable audit, care planning and patient communication tool.
\end{abstract}

\section{BACKGROUND}

Contemporary healthcare provision requires an evidence-based approach and the engagement of patient opinions and desires in order to deliver non-paternalistic and individualised care plans. Two of the primary drivers of the need for change are: 1) the recognition that chronic diseases in an ageing population constitute the majority of the healthcare economic burden and that traditional 'repair' models of care are no longer fit-for purpose; ${ }^{1}$ and 2) that the major risk factors for chronic diseases are modifiable, but require active patient engagement and adherence to effect behaviour change. ${ }^{2}$

Dental Advisor Denplan. Hon Lecturer in Primary Dental Care University of Birmingham, The Stables, Heritage Court, Clifton Reynes, OIney, MK46 5FW; ${ }^{2}$ Managing Director Oral Health Innovations Ltd, Birmingham Research Park, Vincent Drive, Birmingham, B15 2SO; ${ }^{3}$ Chief Dental Officer Denplan Ltd, Denplan Court, Victoria Rd, Winchester, S023 7RG: ${ }^{4}$ Professor of Periodontology and Consultant in Restorative Dentistry The School of Dentistry, College of Medical and Dental Sciences, University of Birmingham, St Chad's Queensway, Birmingham, B4 6NN

${ }^{*}$ Correspondence to: Iain Chapple

Email: i.l.c.chapple@bham.ac.uk

\section{Refereed Pape}

Accepted 10 May 2013

DOI: $10.1038 /$ sj.bdj.2013.738

${ }^{\bullet}$ British Dental Journal 2013; 215: 115-120
In medicine, a wellness model of healthcare delivery involves the identification of risk factors for key diseases in currently healthy patients followed by the provision of personalised preventive care plans aimed at delaying or preventing the onset of signs and symptoms of disease. Cardiovascular disease, for example, remains a major cause of premature mortality accounting for 31\% and $23 \%$ of premature deaths in UK males and females respectively. ${ }^{3}$ The major risk factors are hypertension, hypercholesterolemia, smoking and diabetes, all of which are modifiable by patient driven behaviour change. The wellness approach to address these risk factors in non-diabetic men and women involves the use of age-driven risk scores. In the UK, individuals with a $20 \%$ 10-year risk are treated pharmacologically, whereas those in lower risk groups are supported in behaviour interventions aimed at reducing their blood pressure by reducing dietary salt intake, consuming more fruit and vegetables, increasing exercise, reducing weight and alcohol consumption. ${ }^{4}$ There is good evidence that a combination of simple and cost effective measures may result in 50\% less vascular disease, morbidity and mortality, ${ }^{4}$
Dentistry has lagged behind medicine in respect of risk-based preventive care, largely due to historical models of remuneration within the NHS sector. 'Fee per item' or 'unit of dental activity' funding systems have driven a repair philosophy of surgical intervention rather than a wellness approach. However, in 2009 Steele and colleagues recognised this disconnect and recommended that urgent care should be followed by a formal oral health assessment to evaluate risks for major oral diseases. The latter should inform personalised prevention plans to stabilise the mouth, then advanced care pathways to restore and maintain quality of life should only be implemented when disease risks are managed. ${ }^{5}$

Private dentists and those engaged in capitation-style models are not restricted by the fee charging structure of the NHS which limits the time that they can spend on prevention. This has enabled many to move away from repair-based approaches to remuneration and implement pathways that better engage patients in their own wellness. For the last 12 years Denplan Ltd has operated a voluntary practice accreditation programme called Denplan 
Excel (www.denplan.co.uk). From its inception the Denplan Excel 'Oral Health Score' (OHS) has been an essential component of the programme, designed to motivate patients to actively engage in their own oral healthcare through personalised biofeedback. The OHS measures the oral health status of patients and has developed a significant evidence base over its 12-year history. Aspects included in the OHS derived from research conducted in this area, ${ }^{6,7}$ the weightings for the different components of the OHS were validated, ${ }^{8}$ patient satisfaction with the process was demonstrated ${ }^{9}$ and interand intra-examiner reproducibility was found to be strong. ${ }^{10}$ The Denplan Excel framework provided a setting in which the integration of risk and disease scoring algorithms into a system that also informed suggested capitation fee categories for patients, could be evaluated against an established paper-based system that did not include risk assessment.

Against this background, an online integrated patient assessment system was developed with three groups of output: output 1 - comprised risk categorisation for the major oral diseases (periodontal disease, caries, non-carious tooth surface loss and oral mucosal disease, including oral cancer); output 2 - a set of revised Oral Health Score (OHS) outputs; and output 3 - updated capitation fee guidance.

\section{DEVELOPMENT OF THE ASSESSMENT TOOL FOR PILOTING}

The online tool was developed in collaboration with Oral Health Innovations Ltd (OHI Ltd). OHI Ltd was established as a joint venture with the University of Birmingham in 2007 and profits of $\mathrm{OHI}$ are donated to the UK Oral and Dental Research Trust. OHI Ltd holds the UK and Ireland licence for PreViser technology (www.previser.co.uk) from PreViser Corporation of Washington, USA. PreViser have developed evidencebased online disease risk (caries, periodontal disease, non-carious tooth surface loss and oral cancer) and disease severity (periodontal health and tooth health) scoring and reporting systems for dental teams and their patients. The system uses validated risk factors incorporated into algorithms. The weighting of risk factors in the periodontal disease algorithm has a particularly robust evidence base, ${ }^{13-18}$ whereas the
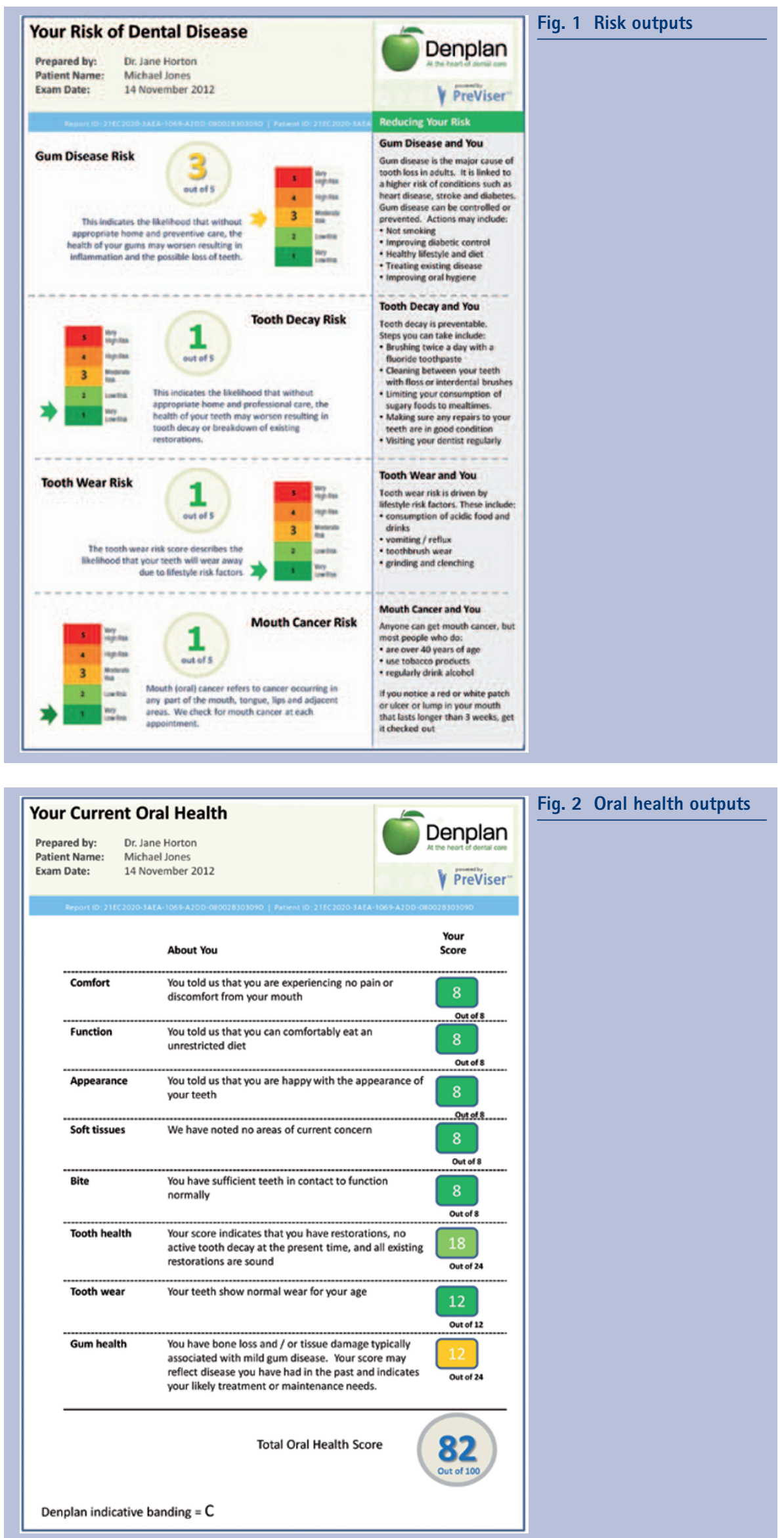

Fig. 2 Oral health outputs

caries, oral cancer and tooth wear risk factors have been individually validated but their weighting within the algorithm has not. PreViser uses both numerical scores and a Red, Amber, Green (RAG) reporting system to aid presentation to patients. 
During 2012, Denplan Ltd worked with OHI Ltd to develop the integrated risk and disease patient assessment tool, building on the strengths of PreViser and the OHS. This tool became known as the Denplan Excel/PreViser Patient Assessment (DEPPA). DEPPA is an online assessment which reports the following to dental teams and their patients:

- Risk outputs (Fig. 1) - the PreViser risk scores (1-5, where 5 is highest risk). Shaded RAG (where red is "very high risk') reporting was utilised for caries risk, periodontal disease risk, risk for non-carious tooth surface loss and oral cancer risk

- Oral health outputs (Fig. 2) - comprises a revised Denplan Excel OHS utilising the PreViser severity scores for periodontal health and tooth health but leaving the other six components and the weightings between all eight components unchanged. ${ }^{8,13}$ The OHS provides a red/ amber/green (RAG) and numerical score for each of the eight components previously validated ${ }^{8,10,14}$ (Fig. 2) to support discussions between dental healthcare professionals and patients. It also provides an overall composite oral health score out of 100 where 100 represents maximum health as a patient motivation tool. The RAG element was added so that severe problems are highlighted in red, moderate problems in amber and health in green

- Fee scale derivation - this module calculates the indicative Denplan fee category as A, B, C, D or E, giving a higher weighting than previously to periodontal disease severity (based on PreViser scoring) and introducing some weighting to oral disease risk (based on PreViser risk scores). Consequently, the significance of past restorative history was downgraded to some extent.

A set of inputs required for each patient assessment to deliver the above reports was developed under the following headings:

1. Patient perceptions (three components of 'function', 'comfort', 'aesthetics'), previously reported under the $0 H S^{8,10}$

2. Periodontal status - previously described under PreViser ${ }^{13,15,16}$

3. Status of teeth - PreViser US Patent no. US8206154; Denplan fee category guidance

\begin{tabular}{|c|c|c|c|}
\hline Component & Scoring method & Scores & Score descriptor \\
\hline Comfort & Patient scored perception & 0,4 or 8 & $\begin{array}{l}0=\text { significant discomfort } \\
4=\text { some discomfort } \\
8=\text { completely comfortable }\end{array}$ \\
\hline Function & Patient scored perception & 0,4 or 8 & $\begin{array}{l}0=\text { significant functional problems } \\
4=\text { some functional problems } \\
8=\text { excellent function }\end{array}$ \\
\hline Appearance & Patient scored perception & 0,4 or 8 & $\begin{array}{l}0=\text { unhappy with appearance } \\
4=\text { some appearance issues } \\
8=\text { happy with appearance }\end{array}$ \\
\hline Soft tissues & $\begin{array}{l}\text { Dentist examination } \\
\text { based on lesions }\end{array}$ & 0,4 or 8 & $\begin{array}{l}0=\text { suspicious lesion(s) requiring referral } \\
4=\text { lesions to monitor, referral not necessary } \\
8=\text { healthy mucosa }\end{array}$ \\
\hline Occlusion & $\begin{array}{l}\text { Dentist examination } \\
\text { based on RDA }\end{array}$ & 0 or 8 & $\begin{array}{l}0=\text { occlusal disharmonies } \\
8=\text { no occlusal disharmonies }\end{array}$ \\
\hline Tooth health & $\begin{array}{l}\text { Dentist examination } \\
\text { of caries and defective } \\
\text { restorations }\end{array}$ & $\begin{array}{l}0,6,12 \\
18 \text { or } 24\end{array}$ & $\begin{array}{l}0=\text { no caries \& no previous restorations } \\
6=\text { no caries and sound restorations } \\
12=\text { mild problems } \\
\text { (up to } 10 \% \text { of teeth need restoring) } \\
18=\text { moderate problems } \\
\text { (10-30\% of teeth need restoring) } \\
24=\text { severe problems } \\
\text { (>30\% of teeth need restoring) }\end{array}$ \\
\hline Tooth wear & $\begin{array}{l}\text { Dentist examination } \\
\text { of NCTSL }\end{array}$ & 0,6 or 12 & $\begin{array}{l}0=\text { excessive (into secondary dentine/pulp) } \\
6=\text { more than expected (into dentine) } \\
12=\text { normal for age (enamel only) }\end{array}$ \\
\hline Gum health & $\begin{array}{l}\text { Dentist examination of } \\
\text { pockets, bleeding and } \\
\text { bone loss }\end{array}$ & $\begin{array}{l}0,6,12 \\
18 \text { or } 24\end{array}$ & $\begin{array}{l}0=\text { severe periodontitis (PreViser algorithm) } \\
6=\text { moderate periodontitis (PreViser } \\
\text { algorithm) } \\
12=\text { mild periodontitis (PreViser algorithm) } \\
18=\text { gingivitis (PreViser algorithm) } \\
24=\text { clinical health }\end{array}$ \\
\hline Total & & 100 & 100 \\
\hline
\end{tabular}

4. Tooth wear - based on Bartlett et al., $2011^{19}$

5. Occlusion - previously reported under the $\mathrm{OHS}^{8,10}$

6. Soft tissues including mouth cancer - previously described under PreViser. ${ }^{18}$

The inputs required were determined by the OHS protocols, the new protocols for Denplan fee category assessment and the data required to operate the PreViser algorithms for disease risks and severity. Approximately 20 of the inputs were based on questions which the patient needed to answer about their oral health perceptions, medical history and lifestyle (see point 1) above). A similar number of inputs were also required based on clinical observations and measurements (see points 2 to 6 above). These are summarised in Table 1. Once clinicians submitted their inputs online, the report was immediately generated. Copies of each patient report could be printed (for filing and/or handing to patients), saved to practice software or emailed to patients with their permission. A mock-up of the report produced is shown in Figures 1 and 2.

\section{STUDY AIMS}

The aim of the pilot study was to seek practitioner feedback on the utility of DEPPA, its perceived value and the need for the system in contemporary preventive care practice.

\section{MATERIAL AND METHODS}

Twenty-five general dental practitioners were recruited to test this pilot version of DEPPA. Ten practice advisers (out of 30) volunteered to participate. An additional 15 participants were recruited from those attending Denplan course on practice enhancement. The final group comprised 25 Denplan dentists, 20 who were Denplan Excel accredited and 5 who were not. A condition of participation was that chair-side Internet access was required in each practice.

Each volunteer was sent a document explaining the development of the pilot version of DEPPA and the protocol for 
the study. Each pilot dentist was provided with a unique three digit code to access the online DEPPA tool and the web address for the site. Pilot dentists were asked to share the report with each patient and explain its content and implications. Dentists were instructed to either file a hard copy or save a digital copy of each report to patient records. Each study dentist was asked to submit 25 assessments each for patients over 19 years of age within four working weeks. Participants were asked only to assess recall patients and not to include new patients. They were given a further week to email their feedback to the primary author using a questionnaire incorporating a 10-point scale (Table 2). Each participant was also encouraged to make free comments to further clarify their scoring.

\section{RESULTS}

In total 640 patient assessments were completed during the four working weeks. Table 3 displays the mean $( \pm \mathrm{SD})$ scores for oral health and disease risk. Only two dentists failed to submit 25 assessments and several performed more than 25 .

The mean OHS was high in this maintenance population, while risk scores varied according to disease entity, with caries risk yielding the highest score. Table 4 sets out the percentage of patients in total classified as being at high risk or very high risk for each condition.

Table 5 shows the percentage of patients placed in each fee category by DEPPA compared with the current spread observed in the Denplan Care database.

Figure 3 shows the average feedback scores received from the 25 pilots, Twentyfour participants submitted verbatim comments (see Table 1 for full questions).

The most common verbatim comments were either:

- Positive and supportive of the tool, eg

'This is an excellent assessment of caries and periodontal disease. It would assist us in developing individual preventive treatments plans and gaining patient compliance (the most difficult part of preventive therapy). I would like to start using it straight away'

- Critical about the ease of use of the on screen inputs, 'Time is a factor as I am sure you appreciate. I did get quicker but it still added 5-10 mins to exam appt'

\section{Table 2 Pilot dentist feedback questionnaire}

Please score the following statements (by highlighting a number) where 0 is total disagreement and 10 total agreement.

I found the assessments straightforward to complete

\begin{tabular}{|l|l|l|l|l|l|l|l|l|l|l|}
\hline 0 & 1 & 2 & 3 & 4 & 5 & 6 & 7 & 8 & 9 & 10 \\
\hline The assessment process is comprehensive \\
\hline 0 & 1 & 2 & 3 & 4 & 5 & 6 & 7 & 8 & 9 & 10 \\
\hline
\end{tabular}

This revised oral health score gives a valid measurement of each patient's oral health status

\begin{tabular}{|l|l|l|l|l|l|l|l|l|l|l|}
\hline 0 & 1 & 2 & 3 & 4 & 5 & 6 & 7 & 8 & 9 & 10 \\
\hline
\end{tabular}

This revised oral health score is an improvement on the 'old' oral health score

\begin{tabular}{l|l|l|l|l|l|l|l|l|l|l|}
\hline 0 & 1 & 2 & 3 & 4 & 5 & 6 & 7 & 8 & 9 & 10
\end{tabular}

The risk scoring generally gave a valid assessment of each patient's future risk of developing disease

\begin{tabular}{l|l|l|l|l|l|l|l|l|l|l}
\hline 0 & 1 & 2 & 3 & 4 & 5 & 6 & 7 & 8 & 9 & 10 \\
\hline
\end{tabular}

The full report is a valuable patient communication aid

\begin{tabular}{l|l|l|l|l|l|l|l|l|l|l}
\hline 0 & 1 & 2 & 3 & 4 & 5 & 6 & 7 & 8 & 9 & 10 \\
\hline
\end{tabular}

The full report is valuable in helping to plan patient care effectively

\begin{tabular}{l|l|l|l|l|l|l|l|l|l|l}
\hline 0 & 1 & 2 & 3 & 4 & 5 & 6 & 7 & 8 & 9 & 10
\end{tabular}

The new Denplan Category scoring places patients fairly into the appropriate price band

\begin{tabular}{l|l|l|l|l|l|l|l|l|l|l|}
\hline 0 & 1 & 2 & 3 & 4 & 5 & 6 & 7 & 8 & 9 & 10 \\
\hline
\end{tabular}

My patients were impressed with the process

\begin{tabular}{l|l|l|l|l|l|l|l|l|l|l|}
\hline 0 & 1 & 2 & 3 & 4 & 5 & 6 & 7 & 8 & 9 & 10
\end{tabular}

Comprehensive patient assessment, such as this, is becoming an essential aspect of quality dental care

\begin{tabular}{l|l|l|l|l|l|l|l|l|l|l}
\hline 0 & 1 & 2 & 3 & 4 & 5 & 6 & 7 & 8 & 9 & 10
\end{tabular}

Table 3 Mean ( \pm SD) Oral Health Score $(\max .100)$ and risk scores (highest risk $=5)-n=640$

\begin{tabular}{|l|l|l|l|l}
\hline OHS & Perio risk & Caries risk & Tooth wear risk & Cancer risk \\
\hline $79.5 \pm 10.8$ & $1.7 \pm 1.0$ & $2.4 \pm 1.7$ & $1.8 \pm 1.1$ & $1.3 \pm 0.6$
\end{tabular}

Table 4 Percentage of patient's classified as high or very high risk (scores 4 and 5 ) $-n=640$

\begin{tabular}{|l|l|l|l|}
\hline Perio & Caries & Tooth wear & Oral cancer \\
\hline $10 \%$ & $30 \%$ & $9 \%$ & $2 \%$ \\
\hline
\end{tabular}

Table 5 DEPPA recommended fee codes compared with current position (A = lowest fee, $E=$ highest fee)

\begin{tabular}{|l|l|l|l|l|l} 
& A & B & C & D & E \\
\hline Current spread & $12 \%$ & $47 \%$ & $34 \%$ & $6 \%$ & $1 \%$ \\
\hline DEPPA recommendation & $15.1 \%$ & $34.3 \%$ & $39.7 \%$ & $9.1 \%$ & $1.8 \%$ \\
\hline
\end{tabular}

- Noted a perceived tendency for DEPPA to overestimate caries risk, 'I found that when caries risk assessing the fact that if a patient had one carious episode in the previous 12 months it often put them in a high risk category which appears to be harsh. They may not have had any decay for some time before and probably won't have decay again for some time to come. The rest of the risk assessment I thought reflected my clinical observations, especially perio.'

\section{DISCUSSION}

This paper reports the feedback of 25 pilot practices to a novel online, integrated risk and disease scoring system, based upon 640 patient assessments performed during November 2012. It also compares future disease risk data with current prevalence data from the ONS adult dental health survey (2009) and compares derived fee bandings for capitation, which are based upon validated risk and disease scores, with the established bandings within the 


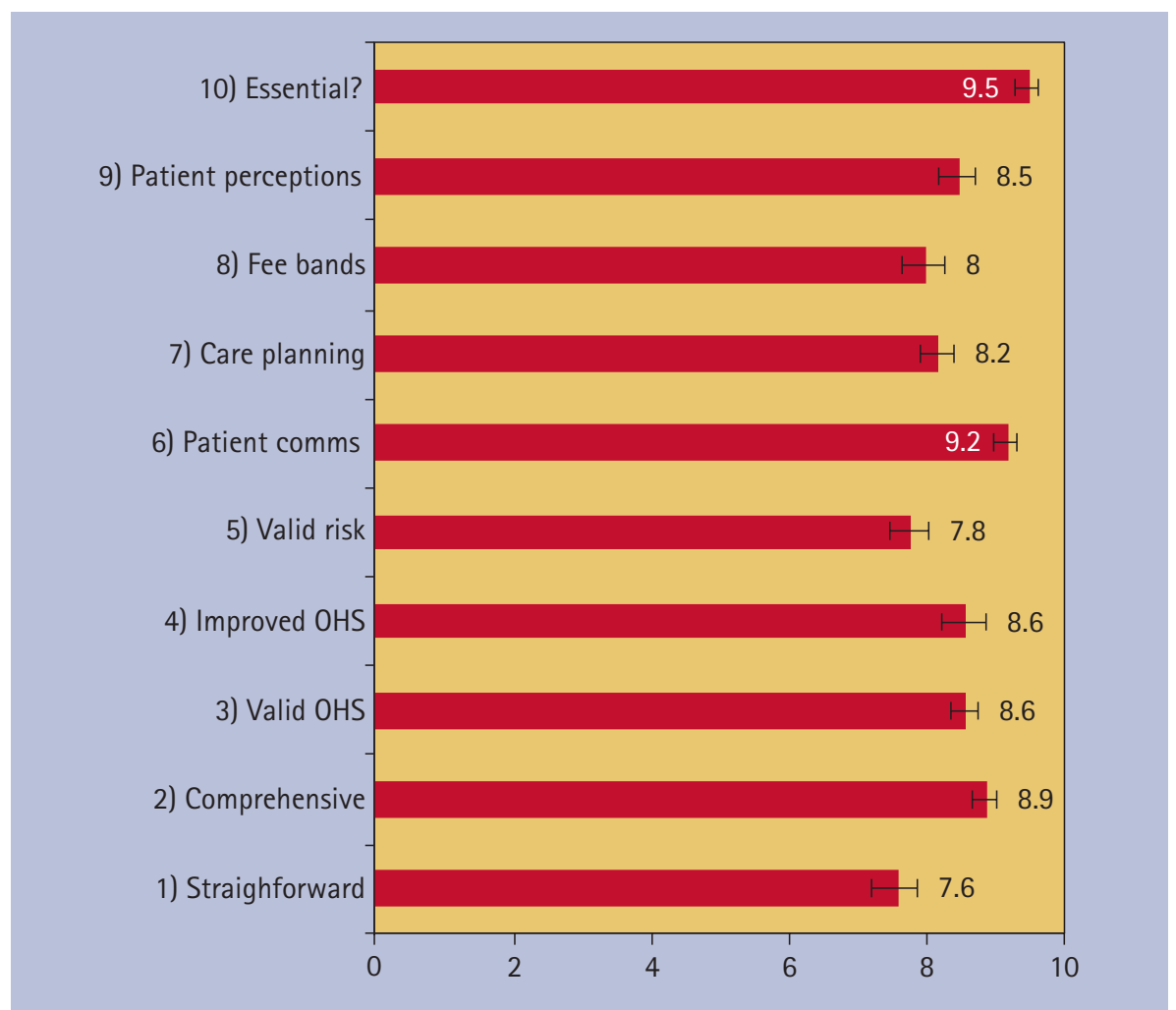

Fig. 3 Mean ( \pm SEM) feedback scores from 25 pilot dentists

Denplan Excel practice system. Overall the response of the participating dentists was very favourable towards the pilot version of DEPPA. The average feedback score across all 10 questions from the 25 participants was 8.5/10 and the group were almost unanimously in support of several aspects. Practitioners clearly believed that comprehensive patient assessment, such as DEPPA, is becoming an essential aspect of contemporary high quality dental care. There was wide acceptance that DEPPA constituted a comprehensive process, served as a valuable patient communication aid, providing personalised biofeedback, which was reported to be well received by patients.

The updating of the original OHS was generally well received and the revised scoring was perceived by the group as appropriate. However, two pilot dentists commented that Oral Health Scores were typically lower that the original paperbased OHS version, implying a more critical assessment. Anecdotally, and from audit data, the authors report that the average scores for the original OHS were around 85 - about six points higher than with DEPPA. The DEPPA version employs tooth health scores derived from PreViser algorithms in such a manner that six points are lost from tooth health once any restoration is in situ (that is, tooth substance has been lost). This is consistent with PreViser periodontal health scores which can never reach the maximum once bone loss has occurred, since predictable and complete bone regeneration remains an elusive goal. Moreover, while a restored tooth may be 'healthy' it remains structurally compromised relative to its pre-disease/restored form and should thus be deemed 'less healthy'.

The feedback scoring and free comments suggested that there was significant support from the pilot group for the changes made to the indicative Denplan fee scoring with $80 \%$ of the pilot dentists scoring this at eight and above. Several participants commented that most patients' fee categories were unchanged, which was reassuring, as the designers wished to avoid large scale disruption to the status quo, unless justified by the severity of periodontal disease or future oral disease risk. Further, the data in Table 5 does not suggest that this more contemporary method of allocating fee categories results in large scale changes for patients. It must be remembered that this scoring is pragmatic, based largely on scientific evidence, but only provides guidance and Denplan dentists ultimately set their own fees and are the final arbiters on which fee category a patient is placed in. The rational here is to retain flexibility of decision-making with the dentist as the final arbiter, allowing them to use their experience and judgement to individualise patient care plans, rather than adopting a restrictive, inflexible and didactic system based upon computer algorithms, which currently cannot replicate human judgement.

Both the feedback scoring and the free comments indicated that several members of the pilot group had concerns about the sensitivity of the caries risk scoring in this pilot version of DEPPA. Forty percent of the pilots scored the question on risk validity (question 5) below $8 / 10$. The data in Table 4 shows that $30 \%$ of these recall patients were classified by this pilot version of DEPPA to be at high risk or very high risk of future caries. This compares to $9 \%$ at high or very high risk of future periodontal disease, 9\% for tooth wear and 2\% for oral cancer. Reviewing the data objectively demonstrates that the data in Table 4 reported from the 640 patients is broadly matched to current disease rates in the UK. Approximately 10\% of UK adults have severe periodontitis and 31\% are reported to have active caries, ${ }^{11}$ while tooth wear prevalence increases from 3\% at 20 years of age to $27 \%$ at 70 years. ${ }^{12}$ Therefore while risk and disease are distinct, but linked parameters, it is reasonable to assume that in the absence of intervention risk broadly translates into disease prevalence and that the DEPPA risk scores very closely reflect current UK disease levels. In response to the concerns over caries risk, the algorithm was modified to discriminate between primary and secondary caries and the system re-piloted by the four practitioners who had expressed concern. The feedback from the re-pilot was unanimous in its support for this modification.

The authors readily accept that, although the evidence base for periodontal disease risk scoring is strong, ${ }^{13-16}$ that for caries risk scoring is less so. There is scope for future work on the validity of caries risk scoring which will be facilitated by the data generated by DEPPA.

Finally, the pilot group were keen to see the 'user-friendliness' of DEPPA evolve from this pilot version. Question 1, concerning this aspect, received the lowest feedback score at 7.6/10. Many useful suggestions were made, on how this could be achieved. Prior to the launch of DEPPA on 
26 April 2013 at the BDA conference, two changes were made in this area: 1) reorganising the inputs so that those questions requiring patients' answers appear together at the start of the data input screen before those inputs requiring data from clinical examination, and 2) creating an optional facility for patients to self-enter these inputs using a tablet system, with the answers being subsequently accessible to the dentist to check and modify. These changes save valuable chair-side time.

One limitation of the current study was that the pilot group were not randomly selected from all Excel general dental practitioners and were a mix of advisors, Excel and non-Excel GDPs in order to provide broad representation, but this does limit the generalisability of the opinions expressed.

\section{CONCLUSIONS}

Having addressed and re-piloted the caries risk score and user friendliness issues raised in the initial pilot, the integrated online oral health and risk assessment tool reported here as DEPPA appears fit for purpose as a pragmatic analytical and biofeedback tool. DEPPA will allow dental teams to measure oral health status, future disease risk and receive ongoing guidance on capitation fee setting. The indications are that DEPPA could be a valuable audit, care planning and patient communication tool, since the centralised data collection format will allow analysis of many thousands of patient inputs in a longitudinal manner, facilitating algorithm modification according to recorded outcomes.

1. Ardell D B. A wellness model for national health insurance. J Health Hum Resour Adm 1983: 5: 321-333

2. Chapple I L C, Hill K B. Getting the message across to periodontitis patients: the role of personalised biofeedback. Int Dent J 2008; 585: 294-306.

3. British Heart Foundation. Heart statistics. Online information available at http://www.heartstats.org (accessed June 2013).

4. Caulfield M. Atheromatous vascular disease and ischaemic stroke in the UK. J Dent 2009 37: S579-581

5. Steele J. An independent review of dental services in England. London: DH publications, 2009. Online report available at $\mathrm{http}: / /$ webarchive.nationalarchives.gov.uk/20130107105354/http://www. dh.gov.uk/prod_consum_dh/groups/dh_digitalassets/documents/digitalasset/dh_101180.pdf (accessed June 2013).

6. Burke F J, Wilson N H. Measuring Oral Health: an historical view and details of a contemporary oral health index (OHX). Int Dent J 1995; 45: 358-370.

7. Ireland R S, Jenner A M, Williams M J, Tickle M. A Clinical Minimum Data Set for General Dental Practice. Br Dent J 2001; 190: 663-667.

8. Burke F J T, Busby M, McHugh S, Delagy S, Mullins
A, Matthews R. Evaluation of an oral health scoring system by dentists in general practice. Br Dent J 2003: 194: 214-218.

9. Burke T, Busby M, Mchugh S, Mullins A, Matthews R. A Pilot Study of Patient's Views of an Oral Health Scoring System. Primary Dent Care 2004; 11: 37-39.

10. Delargy S, Busby M, McHugh S, Matthews R, Burke F J T. The reproducibility of the Denplan Oral Health Score (OHS) in general dental practitioners. Community Dent Health 2007; 24: 105-110.

11. White D.A, Tsakos G, Pitts N.B et al. Adult Dental Health Survey 2009: common oral health conditions and their impact on the population. Br Dent $J$ 2012: 213: 567-572

12. Van't Spijker A, Rodriguez J M, Kreulen C M, Bronkhorst E M, Bartlett D W, Creugers N H (2009). Prevalence of tooth wear in adults. Int J Prosthodont 2009; 22: 35-42.

13. Page R C, Martin J, Krall E A, Mancl L, Garcia R. Longitudinal validation of a periodontal risk calculator. J Clin Periodonto/ 2003: 30: 819-827.

14. Persson R, Mancl L, Martin J, Page R C. (2003). Assessing periodontal disease risk: A comparison of clinicians'assessment versus a computerized tool. J Am Dent Assoc 2003; 134: 575-582.

15. Martin J A, Page R C, Krall Kaye E, Hamed M T, Loeb C F. Periodontitis Severity Plus Risk as a Tooth Loss Predictor. J Periodonto/ 2009; 80: 202-209.

16. Martin J A, Loeb C F, Page R C, Levi P A Jnr. Tooth Loss in 776 Treated Periodontal Patients. J Periodontol 2010; 81: 244-250.

17. Page R C, Martin J A. Quantification of periodontal risk and disease severity using the Oral Health Information Suite (OHIS). Perio in Practice Today 2007; 4: 163-180.

18. Page R C, Martin J A, Loeb C F. The Oral Health Information Suite: Its use in the management of periodontal disease. J Dent Educ 2005; 69: 509-520.

19. Bartlett D, Harding M, Sherriff M, Shirodaria S, Whelton H. A new method to measure toothwear methodology and practical advice. Community Dent Health 2011; 28: 182-187.

\section{Erratum}

\section{Research article (BDJ 2013; 214: 633-642)}

'UK dentists' experience of iatrogenic trigeminal nerve injuries in relation to routine dental procedures: why, when and how often?' In the above research article, the x-axis labels (axis indicating the cause of injury) were missing in Figure 5. Overall frequency of the reported procedures that the injuries were related to. The correct figure is shown below.

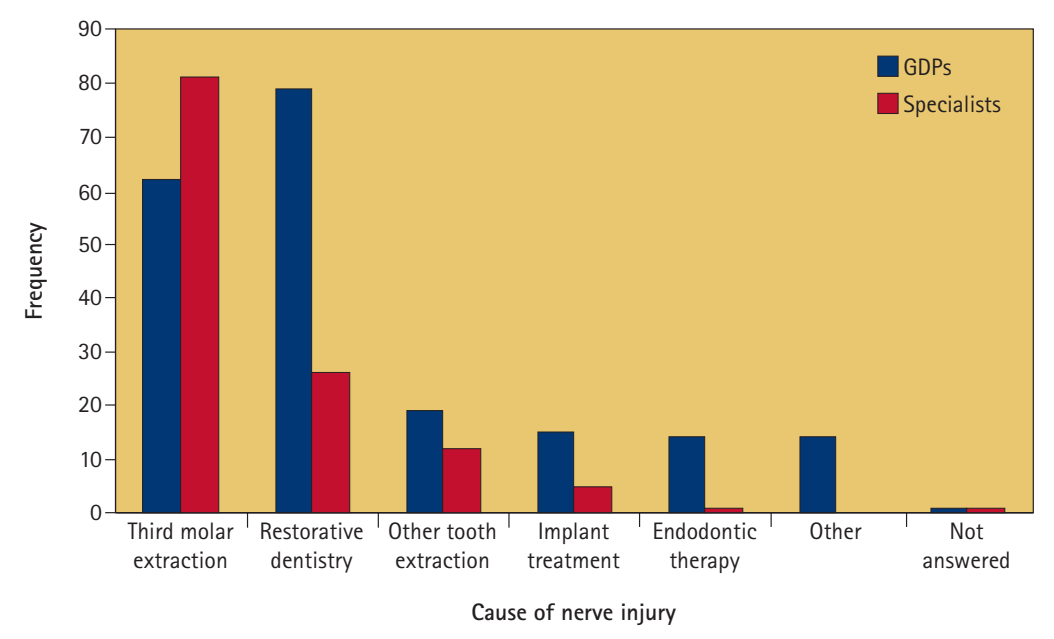

Fig. 5 Overall frequency of the reported procedures that the injuries were related to

We apologise for any confusion caused. 